\title{
Motivating residents to combat invasive species on private lands: social norms and community reciprocity
}

\author{
Rebecca M. Niemiec $^{1}$, Nicole M. Ardoin ${ }^{2}$, Candace B. Wharton ${ }^{3}$ and Gregory P. Asner $^{4}$
}

\begin{abstract}
Invasive species (IS) threaten biodiversity and ecosystem functioning. To achieve landscape-scale reductions in IS and the associated gains for biodiversity, IS control efforts must be expanded across private lands. Enhancing IS control across private lands requires an understanding of the factors that motivate residents to engage or prohibit residents from engaging in efforts to control IS. Drawing from the collective interest model and literature, we sought to understand how a wide range of interpersonal, intrapersonal, and contextual factors might influence resident action around combating the invasive tree albizia (Falcataria moluccana), in the Puna District of Hawai i. To do so, we used a cross-sectional survey of 243 residents and elastic net regression techniques. We found that residents' actions related to IS control were related to their perceptions of social norms and community reciprocity regarding albizia control, as well as their knowledge of effective control strategies and their risk perceptions regarding albizia. These findings suggest that, although common intervention approaches that focus on providing education or subsidies are important, they may be more effective at reducing the spread of IS if coupled with approaches that build community reciprocity and norms.
\end{abstract}

Key Words: community-based conservation; conservation; environmental behavior; Hawai i; invasive species; private lands

\section{INTRODUCTION}

Invasive species (IS) pose a significant threat to native biodiversity, habitat, and ecosystem functioning (Vitousek et al. 1996, Asner et al. 2008, Pyšek and Richardson 2010). IS have led to reductions in native species richness (Gaertner et al. 2009) and half of vertebrate extinctions on island ecosystems in the past century (Tershy et al. 2015). To achieve landscape-scale reductions in the cover and abundance of IS, and the associated gains to biodiversity conservation and ecosystem functioning, control efforts often must be expanded beyond conservation reserves to private lands (Stokes et al. 2006). The recent Predator-Free New Zealand conservation movement, for example, which seeks to achieve widespread reductions in invasive mammal populations, has emerged out of the recognition that control efforts limited to parks and reserves are insufficient for enhancing the nation's native biodiversity (Russell et al. 2015).

Successfully managing IS throughout private lands will require motivating resident engagement in efforts to combat IS (Stokes et al. 2006, Hershdorfer et al. 2007). However, motivating residents to effectively manage IS across private lands may be particularly difficult because the failure of one resident to manage IS on his or her property can create a reservoir for invasion, increasing the costs and difficulty of control for surrounding residents (Klepeis et al. 2009, Epanchin-Niell et al. 2010). IS control across private lands is therefore a transboundary environmental problem, necessitating the coordinated efforts of many landowners (Fiege 2005, Klepeis et al. 2009). To achieve widespread reductions in IS populations, residents must be motivated to not only engage in IS control on their own property, but also participate in collective IS control actions, such as teaching neighbors how to engage in control efforts and applying peer pressure (Graham 2013).

To enhance resident engagement in individual and collective IS control efforts, nonprofit or government agencies often provide education, subsidies, or other interventions within communities (Hershdorfer et al. 2007). The Big Island Invasive Species Committee (BIISC) in Hawai' $\mathrm{i}$, for example, has held numerous community-based workshops to enhance residents' engagement in the control of albizia (Falcataria moluccana), an invasive, nitrogen-fixing tree from the Moluccas, New Guinea, New Britain, and the Solomon Islands (Wagner et al. 1999). However, little is known about how and where such interventions should be implemented to successfully reduce the spread and impacts of IS on private lands.

There is a small but growing literature on the human dimensions of IS management that can begin to provide insight into how interventions may effectively motivate residents. This literature has typically focused on investigating resident involvement in IS control by understanding individuals' attitudes, values, behavioral control beliefs, and knowledge on how to control a species (Aslan et al. 2009, Sharp et al. 2011, Kalnicky et al. 2014 McLeod et al. 2015). Aslan et al. (2009), for example, found that individuals' decisions to engage in control of yellow star thistle (Centaurea solstitialis L.) across private lands were influenced by lack of knowledge of proper control techniques and perceptions of lack of money and time for engaging. Sharp et al. (2011) found that environmental attitudes, as well as knowledge of the impacts of IS, were predictors of people's IS management support. This focus on knowledge, attitudes, and behavioral control beliefs is also reflected in the types of interventions that are used for motivating behavior: often, agencies or nonprofit organizations focus primarily on educating the public about the negative impacts of IS in the hopes of combating invasion (McLeod et al. 2015).

Although attitudes, knowledge, and behavioral control beliefs are likely important factors influencing IS control behavior, numerous social science models and studies suggest that knowledge and attitudes are often insufficient for changing behavior or supporting and maintaining a desired prosocial

${ }^{1}$ Emmett Interdisciplinary Program in Environment and Resources, Stanford University, ${ }^{2}$ Graduate School of Education and Woods Institute for the Environment, Stanford University, ${ }^{3}$ Hawai i Community College, Hilo, ${ }^{4}$ Department of Global Ecology, Carnegie Institution for Science 
behavior (Kollmuss and Agyeman 2002). This research has suggested a multitude of other interpersonal, intrapersonal, and contextual factors that may affect environmental behavior and may thus help inform the design of more effective interventions for enhancing resident IS control activism across private lands (Heimlich and Ardoin 2008). However, the application of social science behavioral models to IS control research is rare (see Prinbeck et al. [2011] as one example), and the application of integrative models that investigate the relative influence of a wide range of potentially important factors identified from the social science literature is even less common (McLeod et al. 2015).

Furthermore, the existing literature on resident engagement in IS control has typically focused on understanding individuals' decisions to control IS on their own land (Aslan et al. 2009, Kalnicky et al. 2014). However, interventions may not reach all residents in a community, leaving many areas uncontrolled (Klepeis et al. 2009, Epanchin-Niell et al. 2010). To truly combat invasion across private lands, therefore, interventions may seek to encourage residents to engage in collective actions, such as contacting neighbors to convince them to engage in control efforts or controlling IS in other areas besides their own property (Graham 2013).

We examine the factors influencing residents' engagement in behaviors to control the invasive albizia tree across private lands in Hawai' i. To do so, we draw on Lubell's (2002) expanded version of the collective interest (CI) model, which was originally developed to understand protest behavior (Finkel and Muller 1998). In applying this model, we build off of recent literature suggesting that IS control across private lands is a collective action problem because reducing IS throughout a landscape requires the actions of many landowners (Hershdorfer et al. 2007, EpanchinNiell et al. 2010, Graham 2013). Individuals may therefore be deincentivized to engage in IS control if others are not also engaging. The CI model specifically seeks to incorporate this collective action context into individuals' environmental decision making by suggesting that in such contexts, individuals are influenced not only by their own knowledge and attitudes, but also by CI variables. These include the following: (1) an individual's value of the public goods provided by environmental activism, which in this case are enhanced biodiversity conservation and public safety provided through communitywide reductions in IS; (2) the extent to which an individual thinks his or her personal actions can affect the provisioning of the public goods; and (3) the extent to which an individual believes others will also contribute to the public goods so that the public goods can ultimately be achieved.

The CI model assumes that individuals are seeking to maximize their expected utility when engaging in various environmental behaviors, so in addition to the CI variables, individuals are assumed to be influenced by the perceived selective benefits and costs to themselves of engaging (Lubell 2002). Therefore, a range of factors found to be important for IS control and other environmental behaviors in the literature, such as attitudes, knowledge, values, demographics, and social norms, can be included as selective costs and benefits.

Incorporating the logic of collective action into models of individual decision making has helped explain other environmental activism behaviors, such as engaging in efforts to combat global warming and air pollution, supporting environmental policies, and signing petitions (Lubell et al. 2006, 2007). If such perceptions relating to the collective action nature of the problem are indeed important to IS control behavior, then interventions focused solely on enhancing knowledge or changing costs may not be as effective in achieving IS reductions across private lands as interventions that also alter perceptions of the collective context.

\section{METHODS}

\section{Case study}

We examined factors influencing resident engagement in IS control through a case study of the management of albizia in the Puna District of Hawai'i. Puna is on the southeastern side of the island of Hawai'i (the "Big Island") and houses just under a quarter of the Big Island's population. The Puna District consists of more than 12 "communities," or housing subdivisions.

Albizia was first brought to Hawai i in 1917 by a botanist and was subsequently planted in the Forest Reserve System throughout Puna and the rest of Hawai'i (Fig. 1; Hughes et al. 2011). Since its introduction, albizia has caused vast ecological and economic damage across both private and public lands (Hughes and Denslow 2005). Albizia is a nitrogen-fixing tree, and in Hawai $i$, it facilitates invasion of damaging exotic understory species, like strawberry guava (Psidium cattlenium), while suppressing native species, such as 'ōhi'a lehua (Metrosideros polymorpha; Hughes and Denslow 2005). Moreover, because albizia grows tall and has low wood density, the tree's massive limbs can fall in high winds or with age (Hughes et al. 2011). The socioeconomic impacts of albizia became especially salient during Tropical Storm Iselle, which ravaged the island of Hawai' $i$ in August 2014. As a result of the high winds brought by the storm, hundreds of albizia trees fell on roads, power lines, and buildings, resulting in a loss of electricity, mobilization, and productivity for several weeks in many subdivisions in Puna (Butler 2014).

Fig. 1. Albizia crowds over power lines in Pi'ihonua, Hawai i (photo provided by Franny Brewer, Big Island Invasive Species Committee).

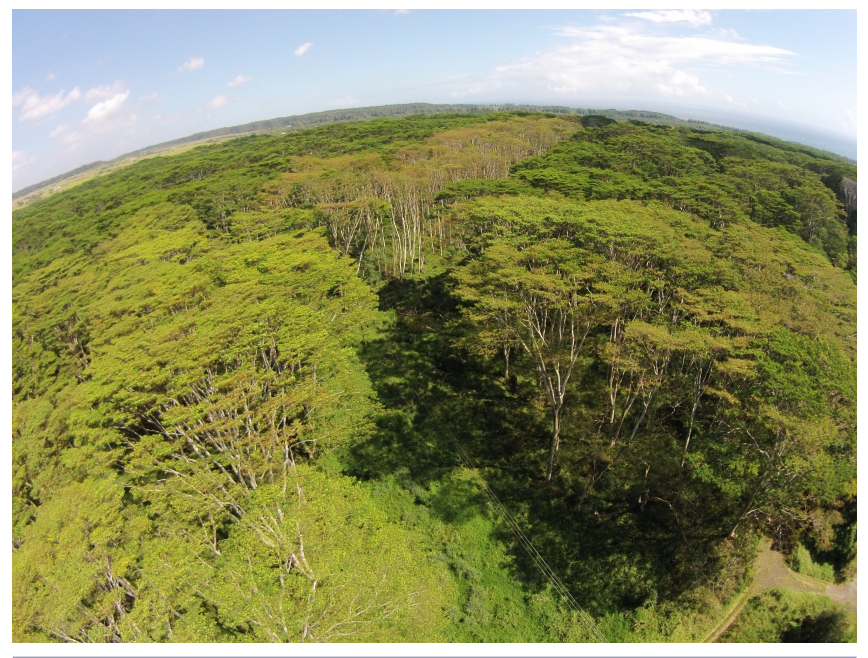


Table 1. Constructs and indicators for the survey organized using the collective interest model.

\begin{tabular}{|c|c|}
\hline Predictor Variable & Indicator on Survey \\
\hline \multicolumn{2}{|l|}{ Individual costs and benefits } \\
\hline Risk (individual) & How great of a risk do you believe albizia poses to your home or other structures on your property? (5-point risk scale) \\
\hline $\begin{array}{l}\text { Knowledge on how to } \\
\text { control }\end{array}$ & I have the knowledge to kill an albizia tree safely and effectively. (Agree/disagree 7-point scale) \\
\hline \multirow[t]{2}{*}{ Behavioral control } & I do not have the money to engage in control. (Agree/disagree 7-point scale) \\
\hline & I do not have the time to engage in control. (Agree/disagree 7-point scale) \\
\hline $\begin{array}{l}\text { Social norms } \\
\text { (subjective) }\end{array}$ & Most people in my community believe that I should take actions to reduce albizia. (Agree/disagree 7-point scale) \\
\hline Network centrality & Since Iselle, have you been asked about your opinion about albizia control? (Y/N) \\
\hline \multirow[t]{2}{*}{ Environmental values } & The balance of nature is delicate and easily upset. (Agree/disagree 7-point scale) \\
\hline & Economic growth should be given priority, even if the environment suffers to some extent. (Agree/disagree 7-point scale) \\
\hline Time on property & How long have you lived on this property? \\
\hline Age & How old are you? (years) \\
\hline Gender & What is your gender? $(\mathrm{M} / \mathrm{F})$ \\
\hline Income & $\begin{array}{l}\text { What was the estimated annual income for your household for } 2014 ?(<\$ 10,000 \$ 10,000-\$ 30,000, \$ 30,001-60,000 \text {, } \\
\$ 60,001-\$ 90,000, \$ 90,001-\$ 100,000,>\$ 100,001)\end{array}$ \\
\hline Education & $\begin{array}{l}\text { What is your highest level of education? (Elementary or some high school, high school, associate degree, college degree, } \\
\text { graduate degree) }\end{array}$ \\
\hline Property size & How large is your property? (acres) \\
\hline Property ownership & Do you own this property? (Y/N) \\
\hline Years on property & How many years have you lived on this property? (years) \\
\hline \multicolumn{2}{|l|}{ Collective interest variables } \\
\hline \multirow[t]{2}{*}{ Risk (collective) } & How great of a risk do you believe albizia poses to Hawai'i's native plants in your community? (5-point risk scale) \\
\hline & How great of a risk do you believe albizia poses to residents in your community? (5-point risk scale) \\
\hline Personal influence & $\begin{array}{l}\text { How confident are you that your personal actions can help reduce the spread of albizia in your community? (5-point } \\
\text { confidence scale) }\end{array}$ \\
\hline $\begin{array}{l}\text { Group efficacy (government } \\
\text { efficacy) }\end{array}$ & Most government officials don’t care about albizia control. (Agree/disagree 7-point scale) \\
\hline \multirow[t]{2}{*}{$\begin{array}{l}\text { Group efficacy (community } \\
\text { reciprocity) }\end{array}$} & $\begin{array}{l}\text { To what extent do you believe that your actions to reduce the spread of albizia will motivate others in your community to } \\
\text { do the same? (5-point likelihood scale) }\end{array}$ \\
\hline & $\begin{array}{l}\text { To what extent do you think others in your community will notice if you kill an albizia tree or sapling? (5-point } \\
\text { likelihood scale) }\end{array}$ \\
\hline \multirow[t]{2}{*}{$\begin{array}{l}\text { Group efficacy (generalized } \\
\text { collective efficacy) }\end{array}$} & $\begin{array}{l}\text { How confident are you that, together, residents can solve the problem of albizia in your community? (5-point confidence } \\
\text { scale) }\end{array}$ \\
\hline & $\begin{array}{l}\text { How confident are you that everyone is working together when it comes to albizia control in your community? (5-point } \\
\text { confidence scale) }\end{array}$ \\
\hline
\end{tabular}

This specific case study of invasion was chosen for two main reasons. First, recent public awareness regarding the impacts of albizia because of Tropical Storm Iselle provided an opportunity to achieve a high survey response rate from the general public. Second, despite the high public awareness about the negative impacts of the species, albizia is still abundant throughout private lands in Puna. Thus, even before conducting surveys, albizia in Puna provided a case suggesting that public awareness of a problematic IS may be necessary, albeit insufficient, for motivating widespread and effective collective action. The case, therefore, allowed the opportunity to explore additional factors that may influence residents' IS control activism.

\section{Dependent variables}

Before beginning surveys, semistructured interviews were conducted with BIISC staff and participants at BIISC workshops to identify the various forms of IS engagement behaviors among Puna residents, as well as key barriers and motivators affecting residents. We determined that individuals could engage in albizia control activism behavior in several ways: killing albizia on their own property; killing albizia elsewhere in the community, such as along roads or in neighbors' property; contacting neighbors to convince them to control albizia; teaching neighbors how to kill albizia; or organizing efforts with neighbors to kill albizia throughout the community.

We measured dependent variables on a continuous but truncated scale, which counted the number of times an individual had engaged in the behavior $(0,1,2,>3$ times). We also created the dependent variable, "total activism behavior," which estimated the number of times an individual engaged in any IS control behavior other than controlling IS on his or her own property.

\section{Independent variables}

Initial interviews with residents led to an examination of 19 independent variables from the CI model of behavior (Table 1). These variables were categorized as either selective costs or benefits or CI variables. All independent variables were measured on 5- or 7-point scales based on the findings of Krosnick and Fabrigar (1997) and because initial piloting of the survey suggested that significant variability existed among participant responses. 


\section{Selective costs and benefits}

For selective benefits of engagement, we included environmental values (adapted from Corbett [2002]) and individual risk posed by albizia to one's property. Drawing on the expanded CI model, we anticipated that individuals with strong environmental values would be more likely to receive psychological or social benefits by engaging in albizia control (Lubell 2002), and those with high perceptions of risk posed by albizia to their property would receive benefits to their personal safety and investments.

We included a measure of subjective social norms as a benefit of engaging; this examined the extent to which individuals believe that others, whom they perceive to be important, care whether they engage in IS control (Rimal and Real 2005). Literature examining social motives for protest participation has highlighted the importance of subjective norms for participation in collective action (Simon et al. 1998); Klandermans and Oegema (1987), for example, found that a key motivator of participation in a mass demonstration was the perception that nonparticipation had to be justified to friends. Individuals who perceive that others care whether they engage in IS control may therefore believe that participating in control efforts would reduce the possibility of social sanctions or increase the possibility of praise by neighbors, friends, or others they deem important in their lives (Simon et al. 1998).

We included a variety of demographic and property variables that, based on the literature, we believed might influence the selective costs or benefits of engaging in IS control (Table 1). We also included knowledge of how to control albizia and behavioral control beliefs regarding lack of time and money. We added a question measuring individuals' social network centrality (adapted from Lubell et al. [2007]) because the literature suggests that individuals with greater network centrality may be better able to obtain information and recruit others, thereby reducing the costs of engaging in IS control behavior (Bodin and Crona 2009).

\section{Collective interest variables}

We included CI variables that specifically allowed for the collective action context of IS control across private lands to be incorporated into an individual's decision making (Table 1). The first CI variable included was collective risk posed by an environmental threat to public goods. We conceptualized this as the perceived collective risk posed by albizia to the public goods of native biodiversity and public safety in one's community.

The CI model also posits that individuals consider their personal influence, or their perceived ability to contribute to the provisioning of the public good through their actions. Previous work has found that perceived personal influence is positively associated with intentions to engage in collective action among members of environmental organizations (Brunsting and Postmes 2002). We conceptualized personal influence as residents' perceptions that their personal actions could make a difference to albizia populations throughout their community.

The third CI variable, referred to as group efficacy, posits that individuals are influenced by the extent to which they believe others in the relevant group will contribute to the public good (Lubell et al. 2007). Although personal efficacy refers to people's perceived ability to contribute to an outcome through their individual efforts, group efficacy refers to people's beliefs in the shared ability of the group to produce desired collective outcomes (Bandura 1998). The CI model assumes that it is rational for an individual to invest effort only if enough others in the relevant group are expected to contribute and, thus, the public good is likely to be achieved. We assumed that there are two relevant types of actors who can influence the extent to which IS are reduced and public goods are provided: government officials, who may pass laws relating to IS control, and other residents within one's community (Lubell et al. 2007).

We therefore included several variables related to citizen and government efficacy adapted from both the sociology and psychology literatures (Table 1). Adapting from Lubell et al. (2007), we used a measure of generalized community reciprocity, which highlights the importance of reciprocity for enhancing community collective efficacy and facilitating collective action (Putnam 2000, Collins et al. 2014). Individuals who believe that their actions will inspire enough others to reciprocate may be more likely to believe that the collective goal of reductions in IS will be achieved, making their efforts worthwhile. Because the communities in Puna vary in terms of total population, access to community associations, and demographics, we hypothesized there may be a diversity of perceptions of community reciprocity among survey respondents. Similarly, we incorporated a visibility measure of how likely others in a community are to notice one's own IS control actions. This item was intended to measure the extent to which there are opportunities within the community for viewing and sharing contributions to the collective, which is likely to influence perceived reciprocity and the ability for residents to act collectively (Janssen 2013). We also applied a measure of government efficacy related to albizia control similar to that used in Lubell (2002). Finally, from the social psychology literature (e.g., Chen 2015), we adapted generalized "collective efficacy" measures, which examine individuals' beliefs that people are generally working together and that the public good can be provided through collective efforts.

\section{Data collection and analysis}

To select survey respondents, we used a combination of purposive sampling techniques, including maximum variation and snowball sampling (Teddlie and $\mathrm{Yu}$ 2007). These approaches allowed us to obtain responses from residents who were highly engaged in albizia control, as well as those who were not, and, as such, we were able to examine differences in contextual, interpersonal, and intrapersonal factors among these groups (Teddlie and Yu 2007). Our maximum variation sampling techniques involved recruiting participants from locations where we would be likely to encounter highly engaged residents, such as community meetings and BIISC albizia control workshops, as well as public locations where we would likely encounter some residents who might be less involved in such efforts; these locations included gas stations, markets, and beach parks. We also used snowball sampling because many people we approached in public locations took extra surveys to give to their highly involved or uninvolved friends and neighbors.

We selected the majority of survey respondents using in-person recruitment techniques at public locations, rather than sampling from phone books or addresses, because we were advised that such an approach would be more socio-culturally appropriate for the study population. We approached individuals between the hours of 7:30 a.m. and 7:30 p.m. during 22 separate recruitment events from 11 June to 25 July 2015. We recruited individuals at 17 
locations throughout Puna, including local hardware stores, BIISC albizia control workshops, community meetings, gas stations, farmers' markets, and beach parks, during weekdays and on weekends. This approach enabled us to recruit residents with varying demographics, interests, hobbies, and potential engagement with albizia control. Throughout the recruitment process, we periodically compared the demographic makeup of our survey population with that of the broader Puna District and reassessed sampling locations if key populations, such as younger residents, were missing. During recruitment, we approached every person exiting the store or, in the case of beach parks, every person sitting at the park.

We pilot tested the survey at the first recruitment event; after testing, we made several changes to clarify wording and improve fluidity based on participant responses. To supplement survey findings, we conducted semistructured interviews with 17 residents. Interviews were conducted with highly engaged residents identified from BIISC workshops, as well as individuals who were not as highly engaged but were identified during the surveying process. During the interviews, we asked residents questions about why they do or do not engage in albizia control behaviors. Interviews were transcribed verbatim and coded based on an a priori coding scheme. The a priori codes, developed based on the literature, were also augmented with emergent codes, as appropriate.

To determine which of the variables were most important to resident behavior, we used elastic net (EN) regression, which is a regularization method (Zou and Hastie 2005). Regularization methods use a penalized loss function rather than minimizing the loss function directly, as is done in ordinary least squares (OLS) regression. McNeish (2015) advocates for the application of regularization methods to the behavioral sciences, particularly when performing variable selection with small to medium-sized samples, to avoid the problem of model overfitting posed by OLS regression and stepwise selection. We follow McNeish's (2015) suggestion given our relatively small sample size and large number of predictor variables.

There are a variety of regularization approaches that may be used to prevent overfitting, such as least absolute shrinkage and selection operator (Lasso) regularization, ridge regression, and EN. Ridge regression applies a penalty function that shrinks coefficients and has the advantage of performing well with collinear predictors; however, it does not perform de facto predictor selection. Lasso is similar to ridge regression but uses a penalty derived from the sum of the absolute values of the regression coefficients, which allows coefficients to be shrunken to zero and thus certain variables to be dropped out of the model. EN uses penalties from both Lasso and ridge regression. We used the EN method because of its increased performance with data sets with correlated predictors (Zou and Hastie 2005). Although Lasso will tend to select only one variable from a group of correlated predictor variables and does not stipulate which variable is selected, EN uses a grouping effect to select correlated predictors together (Zou and Hastie 2005). Because several of our variables were correlated, particularly norms and reciprocity and individual and collective risk, EN enabled us to examine which of these variables were most important for behavior, rather than automatically throwing out correlated variables. $\mathrm{EN}$ is also best used over Lasso regression when the number of predictor variables exceeds the number of samples. We followed the analysis of Wu et al. (2009), who provide methods for using EN penalty to sort through a large set of potentially correlated variables.

For the analysis, we deleted surveys with more than 5 missing questions, and we replaced the remaining missing values in the data set with the mean of the sample. We scaled all predictor variables with $\mathrm{z}$-scores and ran $\mathrm{EN}$ regressions with a 10-fold cross validation at each 0.1 step in alpha between 0 and 1 . The alpha with the smallest root-mean-square error (RMSE) was chosen. At each chosen alpha, we selected the penalty tuning parameter $\lambda$ (lambda) that had the minimum mean cross-validated error. When RMSE from the cross validation selected more than 10 variables, $\lambda 1$ standard error lower was chosen to focus on the most important predictors. We used the variables retained at this $\lambda$ and their corresponding penalized coefficients as the chosen regression model. Because of a lack of methods to calculate $p$ values associated with terms retained in the EN model, we also ran OLS regressions with variables selected from the EN model.

\section{RESULTS}

\section{Surveyed population}

We distributed paper surveys or links to the online web-based survey to 1048 people. Forty-three residents were approached at BIISC workshops and community meetings, and the remaining residents were approached in other public locations. Seventy-two percent of people approached were given a paper version of the survey with a stamped envelope to return by mail, $8 \%$ took the survey in person, and $19 \%$ were given links to the online survey. From Puna residents, we received 285 responses, which were completed online, by mail, or in person. This represents an overall survey response rate of $27 \%$. Approximately $83 \%$ of residents who completed the survey reported that they had been recruited for participation by researchers at a community meeting or public location; the majority of the remaining respondents reported that they were recruited for participation by a friend (11\%). The relatively low response rate given in-person recruitment may have been because of the fact that the population consists of only a small percentage of residents with advanced degrees, and low education populations have been shown to have reduced response rates in other studies (Goyder 1982). Alternatively, the low response rate may have been because of particular attitudes of the population. Interview participants spoke about how many residents in the area enjoyed solitude and did not like being bothered with surveys or other requests.

Of the initiated surveys, 42 were missing more than 5 values, and we noticed that one-third of the surveys missing more than 5 values had respondents who started the survey and did not complete it. We suspect, then, that the high number of missing values may have been a result of the length of the survey. The survey was 2 pages, double spaced, so residents who were not interested in the topic may have lost motivation. We removed all surveys missing more than 5 values from our final analyses, resulting in a total of 243 surveys for regression analysis. We found no significant demographic differences between participants missing more than 5 values and the remaining participants when correcting for multiple comparisons. Our inferences did not change when regressions were run adding in 15 surveys missing fewer than 10 values. 
Survey respondents had a slightly higher median age and education than the general population (Table 2). Many participants were engaged in efforts to reduce albizia in their community (Table 3 ). Almost all participants who had albizia on their property $(42 \%)$ had attempted to control it at least once $(90 \%)$. Because of the extremely small sample of participants who had albizia on their property, but who had not attempted to control it $(10 \%)$, the behavior of removing albizia on property was excluded as a dependent variable.

Table 2. Survey demographics compared to average Puna population, from census data (American Community Survey 2009-2013, for Keaau, Mountain View, Pahoa, and Kurtistown combined; U.S. Census Bureau 2009-2013).

\begin{tabular}{lcc}
\hline \hline Demographic Information & Census Data & $\begin{array}{c}\text { Survey } \\
\text { Population }\end{array}$ \\
\hline Median household income (\$) & 33,993 & $30,000-60,000$ \\
\% Bachelor's degree or higher education & 22 & 38 \\
Median age & 41 & 52 \\
Gender (\% male) & 50 & 49 \\
\hline
\end{tabular}

Table 3. Albizia control activities undertaken by residents within the study region.

\begin{tabular}{|c|c|c|c|}
\hline $\begin{array}{l}\text { Collective Albizia } \\
\text { Control Behavior }\end{array}$ & $\begin{array}{l}\text { Never Engaged } \\
\text { in Behavior }\end{array}$ & $\begin{array}{l}\text { Engaged in } \\
\text { Behavior } \\
\text { Once }\end{array}$ & $\begin{array}{c}\text { Engaged in } \\
\text { Behavior More } \\
\text { Than Once } \\
\end{array}$ \\
\hline $\begin{array}{l}\text { Removed albizia } \\
\text { along roads or other } \\
\text { areas not your } \\
\text { property }\end{array}$ & $47.9 \%$ & $13.8 \%$ & $38.3 \%$ \\
\hline $\begin{array}{l}\text { Spoken to or written } \\
\text { letter to neighbor } \\
\text { about albizia }\end{array}$ & $68.8 \%$ & $9.2 \%$ & $22.1 \%$ \\
\hline $\begin{array}{l}\text { Taught a neighbor } \\
\text { how to control albizia }\end{array}$ & $69.2 \%$ & $13.8 \%$ & $17 \%$ \\
\hline $\begin{array}{l}\text { Organized efforts with } \\
\text { neighbors to combat } \\
\text { albizia in community }\end{array}$ & $75.7 \%$ & $12.3 \%$ & $12 \%$ \\
\hline
\end{tabular}

Most respondents felt that albizia posed at least a moderate threat to residents $(91.7 \%)$ or native plants $(85.3 \%)$ in their community; however, nearly half of respondents indicated albizia posed little or no threat to their own property. Many (31.3\%) responses showed residents lacking knowledge on how to control albizia safely and effectively. Residents' perceptions of community reciprocity regarding albizia control varied as hypothesized, with $60 \%$ of survey respondents indicating that it would be not at all or only slightly likely that others would notice and reciprocate their efforts.

\section{Factors associated with albizia activism}

Before regressions were run, the following independent variables were created as an average of 2 factors (Table 1): collective risk was measured as the risk posed by albizia to both biodiversity and community safety (Cronbach's alpha $=0.74$ ), and behavioral control was measured as both perceptions of lack of time and lack of money for engaging (Cronbach's alpha $=0.73$ ). In addition, the 2 group efficacy items measuring community reciprocity and visibility of actions were combined into 1 measure of reciprocity (Cronbach's alpha $=0.74$ ). Our reciprocity construct, therefore, captures the belief that IS control actions will be both noticed by others within the community and reciprocated. The 2 items measuring environmental values and 2 items measuring generalized collective efficacy were kept as separate variables because of relatively low convergent validity (Cronbach's alpha $=0.39$ and 0.6 , respectively).

Selective costs and benefits

In the EN regression for total albizia activism behavior, knowledge on how to control albizia and subjective norms were the most important selective cost and benefit variables (Table 4). When EN regressions were used to predict specific behaviors, knowledge of how to kill albizia remained an important predictor. Subjective norms remained an important predictor of every behavior except removing albizia in the community. For the variable of organizing efforts with neighbors, environmental values (economic growth) emerged as an important predictor.

Collective interest variables

Collective risk emerged as an important variable for total activism behavior and every individual behavior (Table 4). The importance of collective risk was emphasized in our interviews as well because many residents talked about how albizia posed a threat to their community's roads and power lines. Several participants also talked about the risk posed by albizia to native plants. Individual risk was also important for several variables, including convincing neighbors and organizing efforts with neighbors, but was generally not as important as collective risk.

Community reciprocity emerged as an important predictor of total activism behavior and every behavior except convincing neighbors to control albizia on their property (Table 4). The importance of reciprocity was also brought up several times in interviews: one participant said, "Once I start [removing albizia] they get talking, people see me out there working ... so as much as anything I'm trying to take the lead and get this done and let people come around and other people will follow. When I was in [a different subdivision] nobody noticed, because there weren't any houses close to me. ... But, yea, I think this is a real good place. I think the albizia could be eradicated."

For the behavior of contacting neighbors to encourage them to control IS on their property, surprisingly, perceptions that government officials were not interested in albizia control and everyone was not working together to control albizia were important predictors. This may be because of the fact that Puna has a neighborhood ordinance stating that if a neighbor has a dangerous albizia on his or her property that may cause damage, the government may remove it at the owner's expense. However, funds and labor are lacking to efficiently enforce this ordinance. Thus, some people who have reported a neighbor's tree have not yet witnessed a response from government officials. These people, therefore, may have resorted to contacting their neighbors many times about the albizia because they felt that the government had not been able to help them.

\section{DISCUSSION}

We aimed to better understand the key factors influencing resident activism to combat the invasive albizia tree using the broad framework of the CI model. Applying the CI model provided 
Table 4. Selected independent variables from the collective interest model predicting invasive species control activism, based on elastic net $(\mathrm{EN})$ regression model. Ordinary least squares (OLS) regression was run with variables selected from EN models. Cell entries are unstandardized EN coefficients and unstandardized OLS regression coefficients, with standard errors in parentheses.

\begin{tabular}{|c|c|c|c|c|c|c|c|c|c|c|}
\hline & \multicolumn{2}{|c|}{$\begin{array}{l}\text { Total Activism } \\
\text { Behavior }\end{array}$} & \multicolumn{2}{|c|}{$\begin{array}{l}\text { Removing Albizia in } \\
\text { Community }\end{array}$} & \multicolumn{2}{|c|}{$\begin{array}{c}\text { Teaching Neighbor } \\
\text { How to Control } \\
\text { Albizia } \\
\end{array}$} & \multicolumn{2}{|c|}{$\begin{array}{c}\text { Convincing } \\
\text { Neighbor to Control } \\
\text { on His/Her Property } \\
\end{array}$} & \multicolumn{2}{|c|}{$\begin{array}{l}\text { Organizing Efforts } \\
\text { with Neighbors to } \\
\text { Combat Albizia }\end{array}$} \\
\hline & OLS & EN & OLS & EN & OLS & EN & OLS & EN & OLS & EN \\
\hline Knowledge & $\begin{array}{c}0.53^{* *} \\
(0.07)\end{array}$ & 0.368 & $\begin{array}{c}0.229 * * \\
(0.033)\end{array}$ & 0.134 & $\begin{array}{c}0.146^{* *} \\
(0.024)\end{array}$ & 0.067 & $\begin{array}{l}0.081^{*} \\
(0.029)\end{array}$ & 0.032 & $\begin{array}{r}0.088 * * \\
(0.022)\end{array}$ & 0.068 \\
\hline Risk (individual) & $\begin{array}{c}0.124 \\
(0.107)\end{array}$ & 0.052 & & & & & $\begin{array}{l}0.055 \\
(0.045)\end{array}$ & 0.009 & $\begin{array}{c}0.035 \\
(0.034)\end{array}$ & 0.004 \\
\hline $\begin{array}{l}\text { Environmental values (economic } \\
\text { growth) }\end{array}$ & & & & & & & & & $\begin{array}{l}0.056^{*} \\
(0.025)\end{array}$ & 0.018 \\
\hline Subjective norms & $\begin{array}{l}0.218^{*} \\
(0.093)\end{array}$ & 0.110 & & & $\begin{array}{l}0.066^{*} \\
(0.032)\end{array}$ & 0.025 & $\begin{array}{c}0.056 \\
(0.039)\end{array}$ & 0.018 & $\begin{array}{l}0.054 \\
(0.03)\end{array}$ & 0.036 \\
\hline Risk (collective) & $\begin{array}{c}0.686^{* *} \\
(0.171)\end{array}$ & 0.383 & $\begin{array}{c}0.271 * * \\
(0.071)\end{array}$ & 0.098 & $\begin{array}{l}0.117^{*} \\
(0.052)\end{array}$ & 0.018 & $\begin{array}{l}0.183^{*} \\
(0.074)\end{array}$ & 0.133 & $\begin{array}{l}0.139^{*} \\
(0.054)\end{array}$ & 0.108 \\
\hline Reciprocity & $\begin{array}{l}0.35^{*} \\
(0.16)\end{array}$ & 0.218 & $\begin{array}{l}0.157^{*} \\
(0.075)\end{array}$ & 0.031 & $\begin{array}{l}0.159^{*} \\
(0.056)\end{array}$ & 0.067 & & & $\begin{array}{c}0.072 \\
(0.052)\end{array}$ & 0.038 \\
\hline Government efficacy (lack of) & & & & & & & $\begin{array}{l}0.102^{*} \\
(0.04)\end{array}$ & 0.056 & & \\
\hline $\begin{array}{l}\text { General collective efficacy (working } \\
\text { together) }\end{array}$ & & & & & & & $\begin{array}{l}-0.122^{*} \\
(0.053)\end{array}$ & -0.022 & & \\
\hline $\mathrm{R}^{2}$ (adjusted) & 0.351 & & 0.251 & & 0.247 & & 0.147 & & 0.164 & \\
\hline
\end{tabular}

$* \mathrm{p}<0.05$.

$* * p<0.001$

several insights regarding albizia control activism throughout private lands. First, our results highlight the importance of community reciprocity in motivating resident IS control activism behavior, a factor that has not typically been included in models of IS control behavior. We found that individuals who were more active in combating albizia believed that others in their community would notice and reciprocate their actions to reduce albizia. These results suggest that individual decisions to engage in IS control efforts can be better understood by examining the community-wide collective action context in which an individual is embedded, in addition to examining individual attitudes, values, and behavioral control beliefs.

Our findings also highlight the importance of several selective cost and benefit factors found to be important for IS control behavior in previous studies. Knowledge of how to control albizia safely and effectively was consistently a key factor influencing all forms of activism behavior, supporting Aslan et al.'s (2009) findings of barriers to yellow star thistle control. In addition, perceptions of risk posed by IS were important, supporting previous findings regarding the role of knowledge about the negative impacts of IS (Sharp et al. 2011). Interestingly, we found that residents were more highly motivated by perceptions that albizia was threatening public goods, such as biodiversity and public safety, than their personal property. Many residents spoke about their concern about albizia on both public and private lands that threatened roads, power lines, and other infrastructure in their subdivision. Such perceptions of collective risk may have been heightened by the damage from Tropical Storm Iselle and the subsequent media coverage. These findings suggest that residents do not have to feel that their personal property is threatened by IS to engage; rather, perceptions of risk to public goods in their community can motivate action.
We also found that subjective social norms were associated with IS control activism behavior. The importance of social norms for behavior support the findings of Prinbeck et al. (2011), who found that a common barrier belief to engaging in IS control efforts reported among recreationalists was the perception that no one cared about IS control. Graham (2013) also suggested that encouraging peer pressure and public recognition so that residents had higher perceptions that others care about their IS control actions may enhance weed control efforts across private lands in Australia.

When designing interventions to enhance resident activism to combat invasion, we suggest the importance of improving residents' understanding of the collective risks posed by IS and how to properly manage IS. However, our findings also suggest that such interventions may be more effective if they seek to enhance perceptions of norms and community reciprocity regarding IS control. Community workshops, such as those run by BIISC, in which residents work together to control albizia, have the potential to enhance perceptions of norms and reciprocity by enabling residents to make informal agreements about their control behaviors and see others who care about IS control. Community workshops could be paired with resident participatory mapping of where people have killed IS or contacted landowners, or lawn signs could be developed for residents to announce when they have engaged in IS-related behavior. Such interventions may enable residents to make their efforts more visible and, concurrently, inspire others to conduct IS control in their community. Future research should examine the extent to which such interventions, when coupled with knowledge and skills-building approaches, may enhance resident activism and reduce invasion across private lands. 
In addition to the practical implications our study has for the design of interventions, it raises theoretical questions about the spread of IS across private lands. Because resident activism to combat albizia invasion is linked with perceptions of reciprocity, it is possible that landscapes and community attributes that reduce the potential for residents to interact, build trust, and view each other's IS control efforts may have higher rates of invasion because of lower incidences of resident activism. These landscapes may include areas with high topographic relief, dense vegetation, larger properties, no community associations, or few community events. Future research is needed to examine what types of social landscapes facilitate the spread of IS by reducing the potential for collective action across private lands.

Although our case study was useful for identifying novel factors influencing resident IS activism, we may have been limited by our use of purposive sampling and in-person recruitment. Our sampling techniques may have favored residents who were particularly interested in albizia control, involved in their community, and comfortable being approached by a stranger in a public location. Therefore, the prevalence of certain behaviors and attitudes found in our survey population may not be generalizable to the greater Puna population. The strength of this approach, however, was that it facilitated obtaining sufficient numbers of engaged and nonengaged residents, allowing us to make comparisons of various beliefs and attitudes between these populations.

In addition, because we relied on cross-sectional data, we cannot make inferences about causality. It is possible that residents' activism behavior altered perceptions of social norms and reciprocity, rather than being motivated by perceptions of norms and reciprocity. Future longitudinal studies or experimental work manipulating perceptions of norms and reciprocity is needed to confirm that these factors are indeed drivers, not products, of IS control activism.

Future studies may also build on this work by using a multiple case study approach that could compare the relative importance of different selective costs, benefits, and CI factors given different attributes of both the IS and the social landscape. Such a study could help prioritize which combinations of intervention techniques may be most effective based on the social and ecological context. Building reciprocity, for example, may be important in communities where residents rarely interact, but less important in tight-knit communities with close properties and high visibility.

Our findings from studying albizia invasion in Puna suggest that practitioners and researchers may benefit by moving beyond the sole focus on attitudes, knowledge, and costs when considering resident engagement in IS control. We suggest that considering the role of norms and reciprocity may enhance the ability to understand what types of communities are most at risk of invasion, while also enhancing the ability to combat invasion across private lands.

Responses to this article can be read online at: http://www.ecologyandsociety.org/issues/responses. $\mathrm{php} / 8362$

\section{Acknowledgments:}

We thank the Big Island Invasive Species Committee, which helped introduce us to albizia control issues in Puna. We would particularly like to thank Franny Brewer who provided invaluable guidance for this work. We are grateful for Carly Sponarski's guidance on the design of the survey and Mark Lubell's feedback on applying the collective interest model to invasive species control. We thank Flint Hughes, the Pacific Internship Programs for Exploring Science, Ann Majchrzak, and Peter Vitousek for their support; Andrew Mertens for his statistical help; and Priya Fielding-Singh for her comments on an earlier draft of this manuscript. This work was funded by an NSF Graduate Research Fellowship (DGE-114747) to the first author.

\section{LITERATURE CITED}

Aslan, C. E., M. B. Hufford, R. S. Epanchin-Niell, J. D. Port, J. P. Sexton, and T. M. Waring. 2009. Practical challenges in private stewardship of rangeland ecosystems: yellow starthistle control in Sierra Nevadan foothills. Rangeland Ecology \& Management 62(1):28-37. http://dx.doi.org/10.2111/07-123

Asner, G. P., R. F. Hughes, P. M. Vitousek, D. E. Knapp, T. Kennedy-Bowdoin, J. Boardman, R. E. Martin, M. Eastwood, and R. O. Green. 2008. Invasive plants transform the threedimensional structure of rain forests. Proceedings of the National Academy of Sciences of the United States of America 105 (11):4519-4523. http://dx.doi.org/10.1073/pnas.0710811105

Bandura, A. 1998. Personal and collective efficacy in human adaptation and change. Advances in Psychological Science 1:51-71.

Bodin, Ö., and B. I. Crona. 2009. The role of social networks in natural resource governance: what relational patterns make a difference? Global Environmental Change 19(3):366-374. http:// dx.doi.org/10.1016/j.gloenvcha.2009.05.002

Brunsting, S., and T. Postmes. 2002. Social movement participation in the digital age: predicting offline and online collective action. Small Group Research 33:525-554. http://dx.doi. org/10.1177/104649602237169

Butler, R. A. 2014. Invasive species worsen damage from Hawai'i’s storms. Mongabay, 22 August. [online] URL: http://news. mongabay.com/2014/08/invasive-species-worsen-damage-from-Hawaiisstorms/

Chen, M.-F. 2015. Self-efficacy or collective efficacy within the cognitive theory of stress model: which more effectively explains people's self-reported proenvironmental behavior? Journal of Environmental Psychology 42:66-75. http://dx.doi.org/10.1016/j. jenvp.2015.02.002

Collins, C. R., J. W. Neal, and Z. P. Neal. 2014. Transforming individual civic engagement into community collective efficacy: the role of bonding social capital. American Journal of Community Psychology 54(3-4):328-336. http://dx.doi.org/10.1007/ s10464-014-9675-X

Corbett, J. B. 2002. Motivations to participate in riparian improvement programs: applying the theory of planned behavior. Science Communication 23(3):243-263. http://dx.doi. org/10.1177/107554700202300303 
Epanchin-Niell, R. S., M. B. Hufford, C. E. Aslan, J. P. Sexton, J. D. Port, and T. M. Waring. 2010. Controlling invasive species in complex social landscapes. Frontiers in Ecology and the Environment 8(4):210-216. http://dx.doi.org/10.1890/090029

Fiege, M. 2005. The weedy west: mobile nature, boundaries, and common space in the Montana landscape. Western Historical Quarterly 36:22-47. http://dx.doi.org/10.2307/25443100

Finkel, S. E., and E. N. Muller. 1998. Rational choice and the dynamics of collective political action: evaluating alternative models with panel data. American Political Science Review 92:37-49. http://dx.doi.org/10.2307/2585927

Gaertner M., A. Den Breeyen, C. Hui, and D. M. Richardson. 2009. Impacts of alien plant invasions on species richness in Mediterranean-type ecosystems: a meta-analysis. Progress in Physical Geography 33:319-338. http://dx.doi.org/10.1177/03091$\underline{33309341607}$

Goyder, J. C. 1982. Further evidence on factors affecting response rates to mailed questionnaires. American Sociological Review 47 (4):550-553. http://dx.doi.org/10.2307/2095199

Graham, S. 2013. Three cooperative pathways to solving a collective weed management problem. Australasian Journal of Environmental Management 20(2):116-129. http://dx.doi. org/10.1080/14486563.2013.774681

Heimlich, J. E., and N. M. Ardoin. 2008. Understanding behavior to understand behavior change: a literature review. Environmental Education Research 14(3):215-237. http://dx.doi. org/10.1080/13504620802148881

Hershdorfer, M. E., M. E. Fernandez-Gimenez, and L. D. Howery. 2007. Key attributes influence the performance of local weed management programs in the Southwest United States. Rangeland Ecology and Management 60(3):225-234. http://dx.doi. org/10.2111/1551-5028(2007)60[225:kaitpo]2.0.co;2

Hughes, R. F., and J. S. Denslow. 2005. Invasion by a N2-fixing tree alters function, composition, and structure of wet lowland forests of Hawaii. Ecological Applications 15:1615-1628. http:// dx.doi.org/10.1890/04-0874

Hughes, R. F., M. T. Johnson, and A. Uowolo. 2011. The invasive alien tree Falcataria moluccana: its impacts and management. Pages 218-223 in Y. Wu, T. Johnson, S. Sing, S. Raghu, G. Wheeler, P. Pratt, K. Warner, T. Center, J. Goolsby, and R. Reardon, editors. Proceedings of the XIII International Symposium on Biological Control of Weeds. Warnell School of Forestry and Natural Resources, Athens, Georgia, USA.

Janssen, M. A. 2013. The role of information in governing the commons: experimental results. Ecology and Society 18(4):4. http://dx.doi.org/10.5751/es-05664-180404

Kalnicky, E. A., M. W. Brunson, and K. H. Beard. 2014. A socialecological systems approach to non-native species: habituation and its effect on management of coqui frogs in Hawaii. Biological Conservation 180:187-195. http://dx.doi.org/10.1016/j.biocon.2014.09.044

Klandermans, B., and D. Oegema. 1987. Potentials, networks, motivations, and barriers: steps towards participation in social movements. American Sociological Review 52(4):519-531. http:// dx.doi.org/10.2307/2095297
Klepeis, P., N. Gill, and L. Chisholm. 2009. Emerging amenity landscapes: invasive weeds and land subdivision in rural Australia. Land Use Policy 26(2):380-392. http://dx.doi. org/10.1016/j.landusepol.2008.04.006

Kollmuss, A., and J. Agyeman. 2002. Mind the gap: why do people act environmentally and what are the barriers to proenvironmental behavior? Environmental Education Research 8 (3):239-260. http://dx.doi.org/10.1080/13504620220145401

Krosnick, J. A., and L. R. Fabrigar. 1997. Designing rating scales for effective measurement in surveys. Pages 141-164 in L. Lyberg, P. Biemer, M. Collins, E. De Leeuw, C. Dippo, N. Schwarz, and D. Trewin, editors. Survey Measurement and Process Quality. John Wiley and Sons, Hoboken, New Jersey, USA. http://dx.doi. org/10.1002/9781118490013.ch6

Lubell, M. 2002. Environmental activism as collective action. Environment and Behavior 34(4):431-454. http://dx.doi. org/10.1177/00116502034004002

Lubell, M., A. Vedlitz, S. Zahran, and L. T. Alston. 2006. Collective action, environmental activism, and air quality policy. Political Research Quarterly 59(1):149-160. http://dx.doi. org/10.1177/106591290605900113

Lubell, M., S. Zahran, and A. Vedlitz. 2007. Collective action and citizen responses to global warming. Political Behavior 29 (3):391-413. http://dx.doi.org/10.1007/s11109-006-9025-2

McLeod, L. J., D. W. Hine, P. M. Please, and A. B. Driver. 2015. Applying behavioral theories to invasive animal management: towards an integrated framework. Journal of Environmental Management 161:63-71. http://dx.doi.org/10.1016/j.jenvman.2015.06.048

McNeish, D. M. 2015. Using Lasso for predictor selection and to assuage overfitting: a method long overlooked in behavioral sciences. Multivariate Behavioral Research 50(5):471-484. http:// dx.doi.org/10.1080/00273171.2015.1036965

Prinbeck, G., D. Lach, and S. Chan. 2011. Exploring stakeholders' attitudes and beliefs regarding behaviors that prevent the spread of invasive species. Environmental Education Research 17(3):341-352. http://dx.doi.org/10.1080/13504622.2010.542451

Putnam, R. 2000. Bowling alone: the collapse and revival of American community. Simon and Schuster, New York, New York, USA.

Pyšek, P., and D. M. Richardson. 2010. Invasive species, environmental change and management, and health. Annual Review of Environment and Resources 35:25-55. http://dx.doi. org/10.1146/annurev-environ-033009-095548

Rimal, R. N., and K. Real. 2005. How behaviors are influenced by perceived norms: a test of the theory of normative social behavior. Communication Research 32(3):389-414. http://dx.doi. org/10.1177/0093650205275385

Russell, J. C., J. G. Innes, P. H. Brown, and A. E. Byrom. 2015. Predator-free New Zealand: conservation country. BioScience 65 (5):520-525. http://dx.doi.org/10.1093/biosci/biv012

Sharp, R. L., L. R. Larson, and G. T. Green. 2011. Factors influencing public preferences for invasive alien species management. Biological Conservation 144(8):2097-2104. http:// dx.doi.org/10.1016/j.biocon.2011.04.032 
Simon, B., M. Loewy, S. Stürmer, U. Weber, P. Freytag, C. Habig, C. Kampmeier, and P. Spahlinger. 1998. Collective identification and social movement participation. Journal of Personality and Social Psychology 74(3):646-658. http://dx.doi.org/10.1037/0022$\underline{-3514.74 .3 .646}$

Stokes, K. E., K. P. O’Neill, W. I. Montgomery, J. T. A. Dick, C. A. Maggs, and R. A. McDonald. 2006. The importance of stakeholder engagement in invasive species management: a crossjurisdictional perspective in Ireland. Biodiversity and Conservation 15(8):2829-2852. http://dx.doi.org/10.1007/

$\underline{\text { s10531-005-3137-6 }}$

Teddlie, C., and Yu, F. 2007. Mixed methods sampling: a typology with examples. Journal of Mixed Methods Research 1(1):77-100. http://dx.doi.org/10.1177/2345678906292430

Tershy, B. R., K.-W. Shen, K. M. Newton, N. D. Holmes, and D. A. Croll. 2015. Importance of islands for the protection of biological and linguistic diversity. BioScience 65(6):592-597. http://dx.doi.org/10.1093/biosci/biv031

U.S. Census Bureau. 2009-2013. American Community Survey. U.S. Census Bureau, Washington, D.C., USA. [online] URL: http://factfinder2.census.gov

Vitousek, P. M., C. M. D'Antonio, L. L. Loope, and R. Westbrooks. 1996. Biological invasions as global environmental change. American Scientist 84:468-478.

Wagner, W. L., D. R. Herbst, and S. H. Sohmer. 1999. Manual of the flowering plants of Hawai $i$. University of Hawai' $i$ Press, Honolulu, Hawai i, USA.

Wu, T. T., Y. F. Chen, T. Hastie, E. Sobel, and K. Lange. 2009. Genome-wide association analysis by lasso penalized logistic regression. Bioinformatics 25(6):714-721. http://dx.doi.org/10.1093/ bioinformatics/btp041

Zou, H., and T. Hastie. 2005. Regularization and variable selection via the elastic net. Journal of the Royal Statistical Society: Series B (Statistical Methodology) 67:301-320. http:// dx.doi.org/10.1111/j.1467-9868.2005.00503.x 